\title{
Impacts of Network Embeddedness Structure on Innovation Performance*
}

\author{
Jian Zhaoquan, Wu Zhuoshen, Liu Rong \\ School of Business Administration, South China University of Technology, Guangzhou, P.R.China, 510640 \\ (E-mail: jianzq@163.com, zscut0606@163.com, liurong_myself@126.com)
}

\begin{abstract}
Driven by the trend of global economic integration, informationlization and networking, the era of open innovation has arrived. Relationship network has become a new research approach of probing into the enterprises' innovation, but the results are various. This research draws 114 samples from high-tech enterprises, utilizing structural equation modeling, aiming to explore the relationship among network embeddedness structure, knowledge sharing and innovation performance. Research results show that: (1) Enterprises' relational embeddedness and structural embeddedness have a significant positive impact on innovation performance; (2) Knowledge sharing is the mediating variable in the path of network embeddedness structure on innovation performance. Hoping these results can enrich related theory, and also provide some practicing guidance for enterprises establishing relationship networks to improve innovation performance.
\end{abstract}

Key words: Network embeddedness structure; Relational embeddedness; Structural embeddedness; Knowledge sharing; Innovation performance

\section{Introduction}

In the era of knowledge economy, the competitiveness of enterprises today largely depends on the innovation performance ${ }^{[1]}$. Many important innovation resources are usually not owned by a company, but exist in the network of it ${ }^{[2]}$. The organizations can step over the boundary to integrate the resources and abilities of external partners to improve the ability of enterprise innovation ${ }^{[3][4][5][6]}$. Scholars at home and abroad have done some theoretical and empirical studies on innovation performance and have obtained some achievements based on the perspective of network, but it still exists two aspects of deficiencies. (1) The embeddedness relationship in social network can be divided into relational embeddedness and structural embeddedness, different types of network embeddedness structure may have different impacts on innovation performance, but previous researches did not distinguish them; (2) Resource basic concept deems that knowledge is the most important resource to create additional value. It is limited to learn and create for the organization only depending on its own experience and internal knowledge. How to induce the organizations to share knowledge voluntarily is very difficult. Knowledge sharing is one of the key factors of knowledge management and successful innovation. However, the relevant researches about the relationship of network embeddedness structure and innovation performance basically ignored the impact of knowledge sharing. In order to make up for the deficiencies, the paper explores the mechanisms between the network embeddedness structure, knowledge sharing and innovation performance based on distinguishing the two kinds of network embeddedness structure-the relational embeddedness and the structural embeddedness.

\section{The Oretical Basis and Research Hypotheses}

\subsection{Network embeddedness structure and innovation performance}

Granovetter deemed that most economic behaviors are embedded in personal and social network, through social interactions it produces trading ${ }^{[7]}$. The embeddedness relationship in social network can be divided into relational embeddedness and structural embeddedness. Relational embeddedness focuses on the interactive process to each other. Members can share more information and knowledge through the link between each other. Compared with relational embeddedness, structural embeddedness indicates the overall structure of the network and emphasizes how the relationship and mechanism affect the

\footnotetext{
* Sponsored by the foundations: National Natural Science Foundation Project (70872030; 70972108)
}

Journal on Innovation and Sustainability, São Paulo, vol.02, n.02, p.25 - 33, 2011 
exchange relationship ${ }^{[8]}$. The Paper quotes conclusion from Reowley to define structural embeddedness, utilizes network density to measure structural embeddedness.

The enterprises can get or control the resources from the members in the relational network. But not all the network relationship can be got or used effectively. Enterprises must have strong embeddedness relationship with the members in the network so that they can get these resources. When there exists strong embeddedness relationship (strong ties) among organizations, it will likely increase the quantities of resources transfer, promote the transfer of implicit knowledge and complicated knowledge, encourage innovation and enhance innovation performance ${ }^{[9]}$. Yang et al. thought that network embeddedness does a significant positive impact on the project team's innovation through a research of 60 projects' management department information systems in a university ${ }^{[10]}$. Chen et al. thought that relationship embeddedness does a significant positive impact on service innovation through the research of information services industry in Taiwan. The construction of enterprises' network will enhance value with mutual trust and mutual commitment between members, but not all the network constructions will have a significant effect. Different network constructions will leads different consequences. Based on this, the paper raises the following hypotheses:

Hypothesis 1: Network embeddedness structure does a positive impact on innovation performance. And puts forward the following two affiliated hypotheses:

Hypothesis 1-1: Relational embeddedness does a positive impact on enterprise innovation performance.

Hypothesis 1-2: Structural embeddedness does a positive impact on enterprise innovation performance.

\subsection{Network embeddedness structure and knowledge sharing}

Knowledge sharing refers to the specific knowledge within the organization through the four interaction processes such as socialization, exteriorization, integration and internalization, and through which can make the knowledge between the members be share ${ }^{[11]}$. The concept knowledge sharing between business partners involves three elements: (1) Knowledge sharing subject-it includes the knowledge owner and the knowledge demander and their roles are likely to exchange during the process of knowledge sharing; (2) Enterprise knowledge-it is the object of knowledge sharing; (3) The sharing rules, procedures and methods-their purposes are to share knowledge rapidly, effectively, economically and reasonably and coordinate conflicts of benefit among the participants.

The relationship network between the organizations offers potential opportunities for the enterprises to obtain lots of external knowledge. Thus, certain intensity and intimacy of interactions of the organization relationship network will be good for the organization to build cross-departments knowledge sharing mechanism. Han and Wang selected 41 small teams as samples to make a research about the impacts on knowledge sharing brought by internal interpersonal relationship and discovered that different relationships will do different impacts on the sharing of dominant knowledge and explicit knowledge ${ }^{[12]}$. Based on this, the paper raises the following hypothesis:

Hypothesis 2: Network embeddedness structure does a positive impact on knowledge sharing.

\subsection{Knowledge sharing and innovation performance}

Dominant knowledge and explicit knowledge within and between the organizations are shared by the other members or organizations through all sorts of sharing means, and they will be transformed to the knowledge wealth, which would be very important to enhance the knowledge innovation, organization learning and innovation performance. Lin discovered knowledge sharing circumstances (including interpersonal trust, human motivation, multiple contact and compatible ability, etc) have a positive impact on the final innovation performance through the research on the technology innovation main contributor-R\&D staff $^{[13]}$. Cao and Long selected 95 high-tech enterprises in south China region as samples to 
do empirical research and discovered that knowledge sharing would affect organization performance through affecting organization innovation ${ }^{[14]}$.

On the basic of constructing cooperative innovation game model, Wang deemed that enterprises can enhance the ability of knowledge innovation and technology innovation performance through sharing and complementing the knowledge with other enterprises, institutions of higher learning and scientific research institutions ${ }^{[15]}$. Therefore, the paper raises the following hypothesis:

Hypothesis 3: Knowledge sharing does a positive impact on innovation performance.

\subsection{Mediating role of knowledge sharing in the network embeddedness structure's} impact on innovation performance

$\mathrm{Lu}$ and Liang extracted different industries and distributed questionnaires with the method of pairing with superiors and subordinates, the consequence of which showed that knowledge sharing does a direct and positive impact on innovation performance. Besides, they argued presented knowledge sharing plays a mediating role in the interaction between interpersonal relationship and innovation ${ }^{[16]}$. Synthesizing the literatures review about the relationship between network embeddedness structure, knowledge sharing and innovation performance above, the paper attempts to provide further inferences of their relationship. The paper deems that network embeddedness structure has a positive impact on knowledge sharing and has an indirect impact on innovation performance through knowledge sharing. The paper raises the following hypothesis and tries to test it: Hypothesis 4: knowledge sharing is the mediating variable in the network embeddedness structure's impact on innovation performance.

Summing up the above, the paper shows the framework in Figure1.

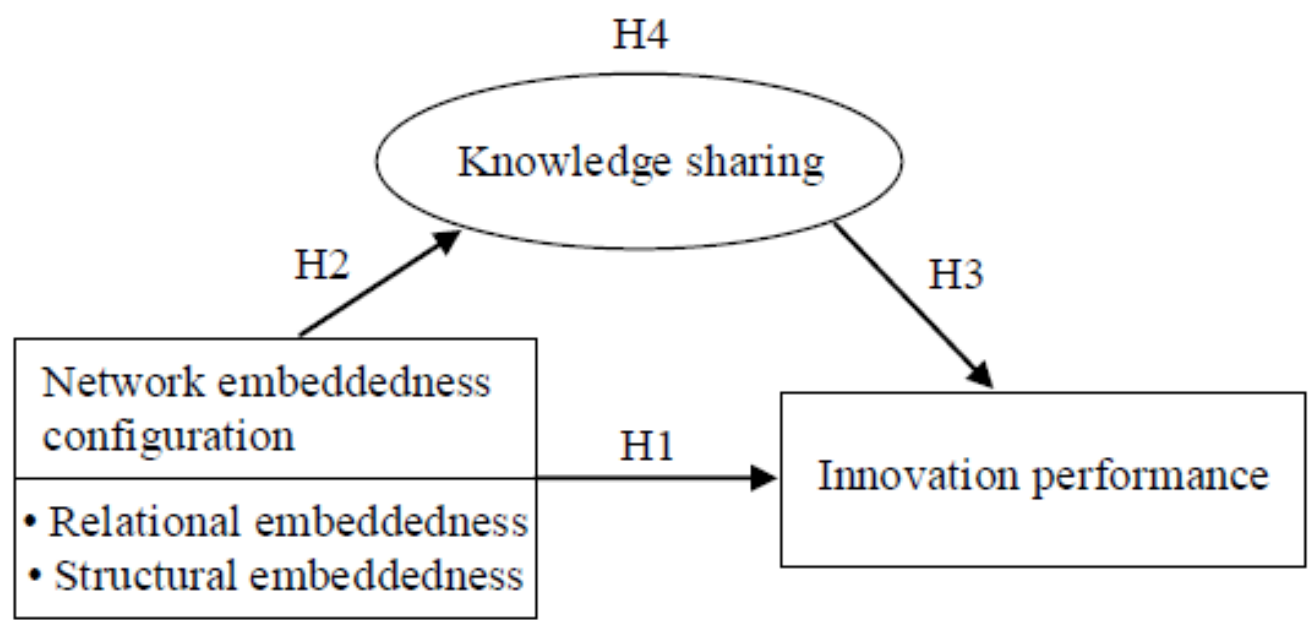

Figure 1 - Research Framework

\section{Research Design \\ 3.1 Data collection}

The subject of the research is how network embeddedness structure and knowledge sharing affect innovation performance. Because innovation ability for high-tech enterprises is particularly important, the research mainly selected high-tech enterprises in south China area as respondents. The enterprises selected include IT manufacturing industry, computer and software industry and communication industry, etc. In order to avoid causing common method variance, the research adopted isolating questionnaires collected method to prevent beforehand, and divided the questionnaires into two parts which are separated from each other. The part related to network embeddedness structure and knowledge sharing was filled in by enterprises' technical directors and mid-senior managers, while the part related to innovation performance was filled in by the former respondents' direct superior.

In reference to the domestic and foreign relevant researches, the research finished 
designing the questionnaires. In order to enhance the reliability and validity of questionnaires, the research selected 10 high-tech enterprises to do preliminary investigation. The research modified and consummated the questionnaire through the detection of internal consistency quotient of the questionnaire's subjects, single subject reliability analysis and KMO value. And then we allied bureau of foreign trade and economic cooperation of Guangzhou, experts of Guangzhou technology market, randomly choose enterprises as samples according to the enterprise yellow pages of south China region. From August to November in 2009, we distributed 500 questionnaires through MBA classroom, e-mail, posting and on-site interview. At last, we received146questionnaires, with a total recovery rate of $29.2 \%$. Removing 32 invalid questionnaires, valid questionnaires are 114 and the final effective rate is $22.8 \%$.

The basic characteristics of samples are as follows. (1) The samples are homogeneous in industries. In the samples, the proportion of software industry is $12.3 \%$, while communication industry of $11.7 \%$, precision industry of $11.0 \%$, semiconductor industry of $10.4 \%$, energy industry of $10.4 \%$ and computer industry of $9.7 \%$. (2) The sample enterprises are generally established early, $22.7 \%$ of them with an establishment time of 7 to 9 years, while $36.4 \%$ of 10 to 20 years and $14.9 \%$ of over 20 years. (3) The sample enterprises have relatively large R\&D investment, $20.1 \%$ of them with an investment ratio (average ratio of $\mathrm{R} \& \mathrm{D}$ investment in total sales in these three years (2007-2009)) of $1.5 \%$ to $2 \%$, while $16.1 \%$ of $2 \%$ to $5 \%$ and $37.0 \%$ of over $5 \%$. (4) The sample enterprises have relatively large dimensions, $17.5 \%$ of them with the number of employees of 501 to 1000 , while $36.4 \%$ of over 1000. As a result, the sample enterprises the research selected meet the study requirements.

\subsection{Variable measure}

In the paper, network embeddedness structure is an independent variable, innovation performance is a dependent variable, and knowledge sharing is a mediating variable. Variables' specific definition is as follows. (1) Network embeddedness structure. It can be divided into relational embeddedness and structural embeddedness based on the research by Granovetter (Granovetter, 1985) and can be measured by three objects (suppliers, customers and academic research institutions) based on the research by Gemünden et $\mathrm{al}^{[17]}$. The paper designs items (altogether 15, and relational embeddedness of 9 while structural embeddedness of questionnaire referring to Uzzi, Gulati and Rowley ${ }^{[18]}$. The variable is measured by Likert Five Scale. (2) Knowledge Sharing. Based on the measurement of knowledge sharing by Fang et al. ${ }^{[19]}$, the research takes knowledge transfer and knowledge receiving as measured variables, defines knowledge sharing as mutual sharing, providing timely and meaningful information among enterprises, customers, suppliers and scientific research institutions, and designs 6 items to measure knowledge sharing among enterprises according to whether enterprises be willing to share industry experience, market and technology information with their partners. All the items will be measured by Likert Five Scale. (3) Innovation performance. synthesizing the research result from Nonaka et al. ${ }^{[11]}$ and Song et al. ${ }^{[20]}$, Combined with the characteristics of Chinese enterprises, and mainly referring to the four perspectives of innovation performance by Jiang ${ }^{[21]}$, the research selects 7 indexes such as patent quantity, new product quantity, new product development cycle, manufacturing cost, project success rate, rate of new product output value and new product annual profit to measure the variable. Also, all the items will be measure by Likert Five Scale.

\subsection{Reliability and validity of the samples}

The research adopts consistency coefficient (Cronbach's alpha) to examine reliability. The Cronbach's $\alpha$ coefficient of all latent variables in the research are over 0.8 and reach acceptable level. So, the questionnaire has good reliability.

Validity includes content validity and structural validity. (1) In content validity, every variable is measured by the scale mainly from mature scale used by many scholars at home and abroad. What's more, we modify some items in the scale according to the results of small-scale interview, consulting relevant experts and preliminary investigation, which 
ensures the questionnaire has good content validity. (2) In convergence validity of structural validity, factor loadings of all latent variables are over 0.7 and reach the acceptable level except that Q1.6 of relational embeddedness is 0.680 and Q3.3 of innovation performance is 0.666 . So, the questionnaire used in the research has relatively good convergence validity. In discriminate validity of structural validity, as it shown in Table 1, every variable's square root of average extraction variance (AVE) is greater than the correlation coefficient belonged to the correlation between it and others variables, which shows the research meets the requirement of discriminate validity.

Table 1 - Descriptive Statistics, Correlation Coefficient and Discriminate Validity of Variables ${ }^{(1)}$

\begin{tabular}{|c|c|c|c|c|c|c|}
\hline variable & mean & $\begin{array}{l}\text { standard } \\
\text { deviation }\end{array}$ & $\begin{array}{c}\text { relational } \\
\text { embeddedness }\end{array}$ & $\begin{array}{c}\text { structural } \\
\text { embeddedness }\end{array}$ & $\begin{array}{l}\text { knowledge } \\
\text { sharing }\end{array}$ & $\begin{array}{c}\text { innovation } \\
\text { performance }\end{array}$ \\
\hline $\begin{array}{c}\text { relational } \\
\text { embeddedness }\end{array}$ & 3.47 & 0.70 & 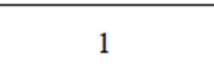 & & & \\
\hline $\begin{array}{c}\text { structural } \\
\text { embeddedness }\end{array}$ & 3.33 & 0.61 & $0.323^{*}$ * $k^{*} *$ & 1 & & \\
\hline $\begin{array}{c}\text { knowledge } \\
\text { sharing }\end{array}$ & 3.05 & 0.67 & $0.326 * *$ & $0.271^{* *}$ & 1 & \\
\hline $\begin{array}{l}\text { innovation } \\
\text { performance }\end{array}$ & 3.23 & 0.64 & $0.568 * *$ & $0.319 * *$ & $0.486^{* * *}$ & 1 \\
\hline $\begin{array}{c}\text { square root of } \\
\text { AVE }\end{array}$ & & & 0.749 & 0.765 & 0.812 & 0.802 \\
\hline
\end{tabular}

\section{Research Results}

As it shown in Table 1, every variable has significant correlation. In additions to this, the reliability and validity of every variable reach acceptable level, so, we can analyze with structural equation modeling (SEM), and start the research from single assumption relation structure model to multi-assumption overall structure model.

\subsection{Hypothesis testing for hypothesis 1}

In the calculation of model data, the research adopts the mean of relational embeddedness and structural embeddedness as the latent variable network embeddedness structure's index. Via the computation of AMOS, path coefficient estimates (standardized values) of the impact on innovation performance brought by network embeddedness structure are shown in Figure 2.

The main goodness-of-fit indexes are shown in Table 2. In the table, we can know the value of $x 2 / \mathrm{df}$ is 1.634 which is far less than 5.0, while the value of CFI is 0.965 which is more than 0.8, the values of AIC and ECVI are less than the values of saturated model and independence model which meet the evaluation criteria of the index. Every fitting index reach the acceptable criteria in SEM. The general fitting condition of the model is relatively good and the model can be accepted. Therefore, the model does not have to be modified. The fully standardized effect's value of network embeddedness structure and innovation performance is 0.645 , and it goes through the significance test.

\footnotetext{
(1) $* * *$ means $\mathrm{p} \leq 0.001, * *$ means $\mathrm{p} \leq 0.01, *$ means $\mathrm{p} \leq 0.05$; and the same below.

(2) network embeddedness structure (NEC), innovation performance (IPE), relational embeddedness (RES), structural embeddedness (SES); and the same below.
} 


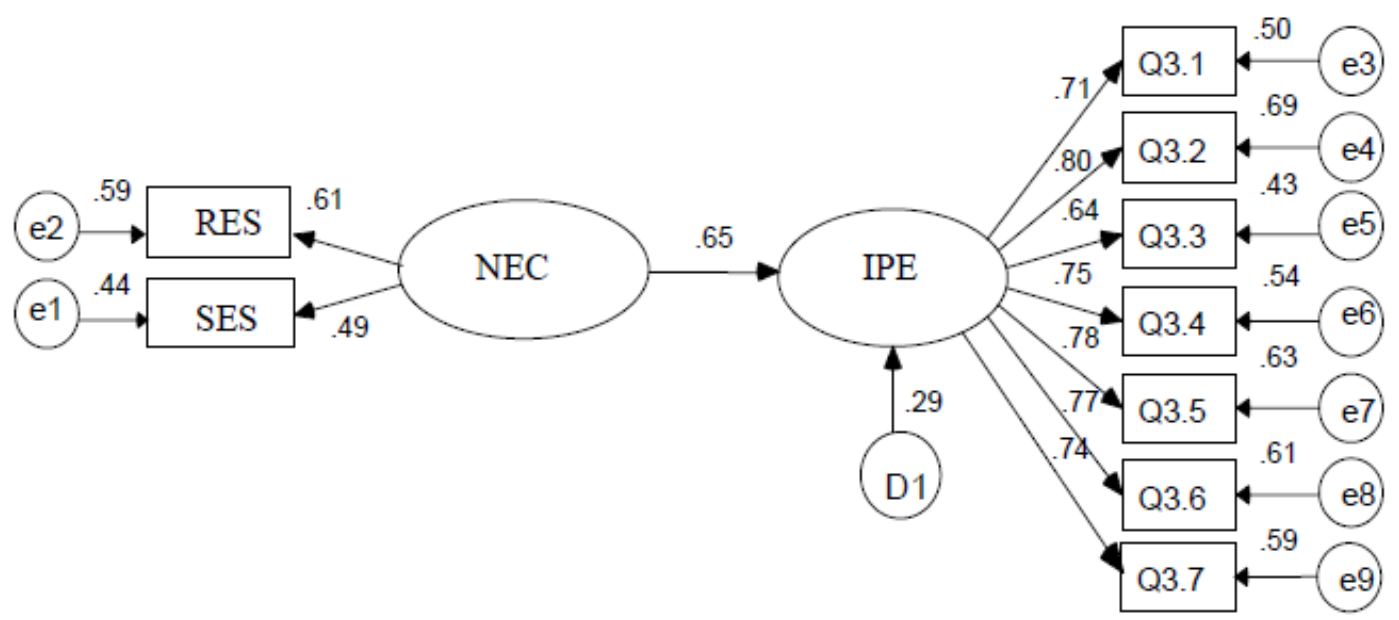

Figure 2 - Relationship Model M of Network Embeddedness Configuration and Innovation Performance

Table 2 - Goodness-of-fit Indexes of Model M

\begin{tabular}{c|ccccc}
\hline Goodness-of-fit index & $x^{2} / \mathrm{d} f$ & CFI & RMSEA & AIC & ECVI \\
\hline Default model & 1.634 & 0.965 & 0.089 & 75.669 & 0.853 \\
Saturated model & - & 1.000 & - & 126.985 & 1.698 \\
Independence model & 15.343 & 0 & 0.211 & 536.645 & 6.382 \\
Criterion & $<5.0$ & $>0.80$ & $<0.1$ & the smaller the better & the smaller the better \\
\hline
\end{tabular}

We can draw a conclusion that there is a significant positive correlation between network embeddedness structure and innovation performance. Hypothesis 1 in the research is supported.

\subsection{Hypothesis testing for hypothesis 1-1 and hypothesis 1-2}

Path estimated coefficients of the impact on innovation performance brought by relational embeddedness and structural embeddedness via the computation of AMOS. In the model, all the factor loadings of impact path are less than 0.95 . The model is reasonable and further analysis can be made. The value of $x 2 / \mathrm{d} f$ is 1.894 , while RMSEA is 0.087 , CFI is 0.934, and the values of AIC and ECVI are less than the values of saturated model and independence model. All the values meet the evaluation criteria. Therefore, the goodness-offit index of the model is relatively good, and the model does not have to be modified. In the model, the fully standardized effect's value of relational embeddedness and innovation performance is 0.403 , while structural embeddedness and innovation performance's is 0.314 . Both of them go through the significant test. Hypothesis 1-1 and Hypothesis 1-2 are supported in the research.

\subsection{Hypothesis testing for hypothesis 2 , hypothesis 3 and hypothesis 4}

There are three equations corresponding to mediating model of the hypothesis model in Figure1.

$$
\begin{aligned}
& \eta=c X+e 1 \\
& M=a X+e 2 \\
& \eta=c^{\prime} X+b M+e 3
\end{aligned}
$$

Adding the mediating variable knowledge sharing into the relationship model of network embeddedness structure and innovation performance, via the computation of AMOS. In the mediating model, all the factor loadings of impact path are less than 0.95 . It is reasonable.

In the mediating model, the values of $x 2 / \mathrm{d} f$, RMSEA and CFI all meet the evaluation criteria. Moreover, the values of AIC and ECVI are less than the values of saturated model and independence model. All fitting indexes of the model reach the acceptable level. 
Therefore, it is not necessary to modify the mediating model, and we can adopt the model to test relevant research hypotheses.

As shown in Table 3, the fully standardized effect's value of network embeddedness structure to innovation performance is 0.315 . Path coefficient of the impact on knowledge sharing brought by network embeddedness structure is 0.633 . The standardized value of the impact on innovation performance brought by knowledge sharing is 0.521 . Those indicates that network embeddedness structure has a significant direct positive impact on innovation performance, while network embeddedness structure has a significant direct positive impact on knowledge sharing, and knowledge sharing has a significant direct positive impact on innovation performance. Therefore, hypothesis 2 and hypothesis 3 in the research are supported.

Table 3 - Path Estimated Coefficient of Variables in Mediating Model

\begin{tabular}{l|ccccc}
\hline \multicolumn{1}{c|}{ Path } & Estimate & Standard estimate & S.E. & C.R. & P \\
\hline $\begin{array}{l}\text { Network embeddedness structure } \\
\text { Innovation performance }\end{array}$ & 0.334 & 0.315 & 0.112 & 3.184 & **** \\
$\begin{array}{l}\text { Network embeddedness structure } \rightarrow \\
\text { Knowledge sharing }\end{array}$ & 0.642 & 0.633 & 0.150 & 1.866 & $*$ **** \\
$\begin{array}{l}\text { Knowledge sharing } \\
\text { Innovation performance }\end{array}$ & 0.508 & 0.521 & 0.107 & 1.034 & $* * *$ \\
\hline
\end{tabular}

In order to explain the relationship between the variables more roundly and clearly, the research further decomposes the effects on the basic of what have been done above. Effect decomposition includes direct effect and indirect effect.

The direct effect is measured by the path coefficient from cause variable to outcome variable, and indirect effect can be measured by the product of the two path coefficients (when there is only an mediating variable) ${ }^{[22]}$. We can know in Table 4 that the total effect on innovation performance brought by network embeddedness structure in model M exactly equals the direct and indirect total effect on innovation performance brought by network embeddedness structure in mediating model. The ratio of indirect effect and direct effect is $0.63 \times 0.52 / 0.32=102.38 \%$. Indirect effect is a little bigger than direct effect. Therefore, hypothesis 4 is supported.

Table 4 - Standardized Effect Between Variables

\begin{tabular}{l|ccc}
\hline \multicolumn{1}{c|}{ Path } & $\begin{array}{c}\text { Standardized } \\
\text { direct effect }\end{array}$ & $\begin{array}{c}\text { Standardized } \\
\text { indirect effect }\end{array}$ & $\begin{array}{c}\text { Standardized } \\
\text { total effect }\end{array}$ \\
\hline $\begin{array}{l}\text { Network embeddedness structure } \rightarrow \\
\text { Innovation performance }\end{array}$ & 0.315 & 0.330 & 0.645 \\
$\begin{array}{l}\text { Network embeddedness structure } \rightarrow \\
\text { Knowledge sharing }\end{array}$ & 0.633 & $/$ & 0.633 \\
$\begin{array}{l}\text { Knowledge sharing } \\
\text { Innovation performance }\end{array}$ & 0.521 & $/$ & 0.521 \\
\hline
\end{tabular}

\section{Conclusion}

The research extracts 114 high-tech enterprises as study objects. Through the literatures review and theoretical deduction, the research excavates the interaction mechanism among network embeddedness structure, knowledge sharing and innovation performance in depth. The analysis results show that: (1) Relational embeddedness and structural embeddedness of network embeddedness structure both have a significant positive impact on innovation performance; (2) Knowledge sharing has partial mediating impact on the effect path from network embeddedness structure to innovation performance.

The research results expand the cognition of network embeddedness structure and current innovation theory in two aspects. (1) The embeddedness relationship in social network can be divided into two dimensions-relational embeddedness and structural embeddedness, but previous researches mostly only selected one of the two dimensions to study, and 
structural embeddedness was mostly to be selected. The two dimensions are combined to study their impact on innovation performance. Through empirical analysis, we discover that both structural embeddedness and relational embeddedness of the enterprises have a significant positive impact on innovation performance. (2) The research adds knowledge sharing into the study of the effect on innovation sharing brought by network embeddedness structure, and builds a new model. The analysis finds out knowledge sharing has partial mediating impact on innovation performance. Knowledge sharing can improve the efficiency and benefit of cooperation, enhance mutual trust, so that both sides can get useful complementary information with lower cost and raise the success rate and profitability of innovation projects.

The results of the research have an important significance in management practice. (1) Customers can provide enterprises a new market demand, greatly enhance innovative market value and bring more customer resources to the enterprises. Cooperation with suppliers can customize the raw materials necessary for enterprises' innovative products, get corresponding technical support, even can get lower cost and exclusive resources, and shorten the cycle of innovation. Cooperation with academic research institutions can get support from exterior to enhance the capacity of enterprises' independent R\&D, reduce the risk of R\&D. (2) Because relational embeddedness has a significant positive impact on innovation performance, enterprises should pay attention to the management of relationship quality with partners in the network. (3) Enterprises should pay attention to knowledge sharing, set up a special interactive organization, manage the internal information in classifications in order to eliminate habitual defense behaviors, and entirely and timely master every aspect of the partners so that the risk brought by asymmetric and incomplete information can be reduced.

Although the research reveals the relationship among network embeddedness structure, knowledge sharing and innovation performance, there are still some deficiencies. First, the research samples are only selected form the high-tech enterprises in South China, so, the universality of research results has yet to be confirmed in the other areas and industries. Second, the mediating role of knowledge sharing is not very significant. Whether there are some other moderator and mediating variables in the effect process from network embeddedness structure to innovation performance has yet to be further studied, etc.

\section{References}

[1] Can Peng, Ling Yang. Empirical Study on the Relationship among Technology Capability, Innovation Strategy, and Innovation Performance[J]. Science Research Management, 2009, 30(2): 26-32 (In Chinese)

[2] Afuah A. Innovation Management: Strategies, Implementation and Profits[M]. NY: Oxford, 2003

[3] Hanna V., Walsh K. Small Firm Networks: A Successful Approach to Innovation?[J]. R\&D Management, 2002, 32(2): 201-207

[4] Perks H., Jeffery R. Global Network Structure for Innovation: A Study of International Fiber Innovation[J]. R \& D Management, 2006, 36(1): 67-83

[5] Heimeriks K. H., Duysters G. Alliance Capability as a Mediator Between Experience and Alliance Performance: An Empirical Investigation into the Alliance Capability Development Process[J]. Journal of Management Studies, 2007, 44(1): 25-49

[6] Capaldo A. Network Structure and Innovation: The Leveraging of a Dual Network as a Distinctive Relational Capability[J]. Strategic Management Journal, 2007, 28(4): 585-608

[7] Granovetter M. S. Economic Auction and Social Structure: The Problem of Social Embeddedness[J]. American Journal of Sociology, 1985, 91(3): 481-510

[8] Moran P. Structural VS Relational Embeddedness: Social Capital and Managerial Performance[J]. Strategic Management Journal, 2005, 26(6): 1129-1151

[9] Xu Guannan. The Study of the Impact on Technological Innovation Performance Brought by Relational Embeddedness[D]. Zhejiang University, 2008 (In Chinese)

Journal on Innovation and Sustainability, São Paulo, vol.02, n.02, p.25 - 33, 2011 
[10] Yang Hengli. Creativity of Student Information System Projects: From the Perspective of Network Embeddedness[J]. Computers \& Education, 2010, 54(1): 209-221 (In Chinese)

[11] Nonaka I., Takeuchi H. The Knowledge-creating Company[M]. New York: Oxford University Press, 1995

[12] Han Yan, Wang Anmin. The Influence of Interpersonal Relationship on Knowledge Sharing in Small Teams[J]. Science of Science and Management of S.\& T., 2008, (10): 124126 (In Chinese)

[13] Lin Zhaoli. Relationship Between R\&D's Knowledge Sharing Situation and R\&D Performance[D]. National Sun Yat-sen University: 2002 (In Chinese)

[14] Cao Keyan, Long Junwei. The Relationship of Organizational Culture, Knowledge Sharing and Organizational Innovation[J]. Studies in Science of Science, 2009, 27(12): 18691876 (In Chinese)

[15] Wang Juanru. Study on the Enterprise Cooperation Innovation Based on Knowledge Sharing[J]. Science \& Technology Progress and Policy, 2009, 26(15): 135-137 (In Chinese)

[16] Lu Lin, Liang Xueling. The Mediating Effect of Knowledge Sharing Between Interpersonal Interactions and Innovation[J]. Nankai Business Review, 2009, 12(1): 118-123 (In Chinese)

[17] Gemünden H. G., Ritter T., Heydebreck P. Network Structure and Innovation Success: An Empirical Analysis in German High-tech Industries[J]. International Journal of Research in Marketing, 1996, 13(4): 449-462

[18] Gulati R. Where Do Interorganizational Networks Come From[J]. The American Journal of Sociology, 1999, 104(5): 1439-1493

[19] Fang Shirong et al. An Empirical Study of New Product R\&D Performance Relationship Management Approach[J]. Journal of Technology Management, 2004: 43-55 (In Chinese)

[20] Song S. M., Parry M. E. What Separates Japanese New Product Winners From Losers[J]. Journal of Product Innovation Management, 1996, (13): 422-439

[21] Jiang Jian. Empirical Research of the Relationship Between Supplier's Involvement in Technology Innovation and Manufacturer's Innovation Performance[D]. Zhejiang University, 2004 (In Chinese)

[22] Wen Zhonglin, Chang Lei, Liu Hongyun. Testing and Application of the Mediating Effects[J]. Acta Psychological Sinica, 2004, 36(5): 614-62 (In Chinese) 